\title{
PELAKSANAAN PERWAKAFAN TANAH MILIK SESUDAH BERLAKUNYA UNDANG-UNDANG NOMOR 41 TAHUN 2004
}

\author{
Tri Hardoyo \\ Universitas Nahdlatul Ulama Surakarta
}

\begin{abstract}
Abstrak
Tulisan ini bertujuan untuk mengetahui pelaksanaan perwakafan tanah milik di KUA Kecamatan Kalikotes menurut Undang-undang Nomor 41 Tahun 2004; dan untuk mengetahui apa saja yang timbul dalam perwakafan tanah milik di KUA Kecamatan Kalikotes setelah berlakunya Undang-undang Nomor 41 Tahun 2004. Penelitian ini menggunakan pendekatan kualitatif. Hasil penelitian menunjukkan pelaksanaan perwakafan tanah milik yang terjadi di Kecamatan Kalikotes Kabupaten Klaten yang penulis peroleh dalam penelitian, dapat menyimpulkan bahwa secara umum sudah sesuai dengan Undang-undang Nomor 41 Tahun 2004. Hal ini terbukti dari pelaksanaan perwakafan tanah milik sesuai dengan prosedurnya yang berlaku seperti dari awal proses sampai terbitnya sertifikat tanah wakafnya. Permasalahan dalam pelaksanaan perwakafan tanah milik adalah ketika sertifikat sudah jadi pada tanggal 28 Pebruari 2004 dengan HM nomor 1554 yang luasnya $183 \mathrm{~m}^{3}$ atas nama Suwisno, semua ahli waris berkehendak menjadi waqif yang akan mengikrarkan tanah wakaf tersebut. Hal ini yang tidak sesuai dengan Undang-undang.
\end{abstract}

Kata kunci: Wakaf, Perwakafan Tanah

\section{Abstract}

This paper aims to determine the implementation of land acquisition in KUA Kalikotes Subdistrict according to Law No. 41 of 2004 and what arises in the representation of the property in KUA Kalikotes subdistrict after the 
enactment of Law No. 41 of 2004. This research uses a qualitative approach. The study results showed that the implementation of land acquisition that occurred in Kalikotes District of Klaten Regency, which the author obtained in the study, can conclude that, in general, it is following Law No. 41 of 2004. Evidence from the implementation of the representation of owned land following applicable procedures, such as from the beginning of the process until the issuance of the waqf land certificate. The problem is the implementation of property representation. When the certificate is finished on February 28, 2004, with HM number 1554, which is $183 \mathrm{m3}$ in the name of Suwisno, all heirs will become waqif, who will pledge the waqf land. This is not following the law.

Keywords: Waqf, Land Waqf

\section{A. PENDAHULUAN}

Wakaf merupakan salah satu potensi sumber dana publik yang penting dan besar sekali manfaatnya bagi kepentingan agama dan umat, khususnya Islam. Antara lain untuk pembinaan kehidupan beragama dan peningkatan kesejahteraan umat Islam, terutama bagi orang-orang yang tidak mampu, cacat mental/fisik, orang-orang yang sudah lanjut usia, dan sebagainya.

Wakaf baru diatur dalam bentuk Undang-Undang pada tanggal 27 Oktober 2004, yaitu saat disahkan Undang-undang Nomor 41 Tahun 2004 tentang Wakaf. Pembentukan Undang-undang Nomor 41 Tahun 2004 ini dimaksudkan pula untuk memenuhi kebutuhan hukum dalam rangka pembinaan hukum nasional. Pada dasarnya ketentuan mengenai perwakafan berdasarkan syariah dan peraturan perundang-undangan dicantumkan kembali dalam Undang-undang Nomor 41 Tahun 2004 dengan beberapa ketentuan yang baru. Dikemukakan pula dengan berlakunya Undang-undang Nomor 41 Tahun 2004 tersebut, semua peraturan perundang-undangan yang mengatur mengenai perwakafan masih tetap berlaku sepanjang tidak bertentangan dan/atau belum diganti dengan peraturan yang baru berdasarkan Undang-undang Nomor 41 Tahun 2004.' Dari konsiderans

\footnotetext{
${ }^{1}$ Artikel Skripsi. Dosen Pembimbing: Dr. Merry E. Kalalo, SH, MH; Godlieb N. Mamahit, SH, MH; Berlian Manoppo, SH, MH
} 
menimbang dapat diketahui bahwa Undang-undang wakaf yang diatur dalam Undang-undang Nomor 41 Tahun 2004 merupakan Undang-undang pertama kali yang mengatur ketentuan wakaf di Indonesia.

Mengingat akan pentingnya wakaf, maka Pemerintah memprioritaskan pengaturan tentang wakaf. Dengan wakaf, umat Islam dapat membantu secara positif pembangunan manusia seutuhnya bagi seluruh masyarakat Indonesia. Wakaf mempunyai arti yang sangat penting dalam pengembangan Islam, betapa pentingnya arti wakaf bagi waqif maupun bagi agama dapat dilihat dalam Undang-undang Nomor 41 Tahun 2004 Pasal 1 ayat (1) yang berbunyi wakaf adalah perbuatan hukum waqif untuk memisahkan dan/atau menyerahkan sebagian harta benda miliknya untuk dimanfaatkan selamanya atau untuk jangka waktu tertentu sesuai dengan kepentingannya guna keperluan ibadah dan/ atau kesejahteraan umum menurut syari'ah.

Dalam Islam diajarkan bahwa Allah menjanjikan pahala yang besar bagi orang-orang yang melakukan ibadah kepadaNya. Firman Allah surat alBaqarah ayat 261.

Penataan kehidupan mayarakat harusnya bisa dikelola secara baik dengan menjamin kualitas kehidupan yang dapat mewujudkan martabat kemanusiaan melalui pemanfaatan harta wakaf secara maksimal. Sebagai bagian dari ajaran Islam, wakaf menandai adanya perhatian Islam yang tinggi atas masalah-masalah kemasyarakatan dari kehidupan manusia di dunia. Dalam rangka inilah, ajaran wakaf sesungguhnya terkait dengan masalah sumber daya alam yang merupakan harta kekayaan dan sumber daya manusia sebagai subjek pemanfaatan. Diantara permasalahnya yang terpenting adalah perawatan, pengembangan, pelestarian, pengolahan, pengelolaan, pemanfaatan, pemerataan dan pengaturan yang baik dan adil untuk memenuhi kebutuhan hidup yang lengkap, yang pada umumnya disebut kemakmuran, kesejahteraan dan kebahagiaan dalam jangka pendek dan jangka panjang dalam kehidupan manusia. ${ }^{2}$

Sejak terjadi krisis dalam kehidupan bangsa kita yang dipicu oleh krisis ekonomi, maka peran wakaf menjadi semakin penting, sebagai salah

${ }^{2}$ Departemen Agama RI Ditjen Bimas Islam dan Penyelenggaraan Haji, Pedoman Pengelolaan dan Pengembangan Wakaf, (Jakarta: t.np., 2004), hlm. 65. 
satu instrumen untuk meningkatkan kesejahteraan masyarakat. Pengelolaan wakaf tidak statis, melainkan selalu berkembang sejalan dengan dinamika dan perubahan di masyarakat. Dalam kaitannya dengan bidang wakaf, Pemerintah memfokuskan perhatian pada penataan administrasi wakaf yang memberi kepastian hukum bagi pewakaf, nadzir (pengelola wakaf) dan objek wakaf, serta mendorong pemanfaatan aset-aset wakaf yang tidak produktif menjadi produktif.

Salah satu langkah strategis untuk mewujudkan kesejahteraan umum, perlu meningkatkan peran wakaf sebagai pranata keagamaan yang tidak hanya bertujuan menyediakan berbagai sarana ibadah dan sosial, tetapi juga memiliki kekuatan ekonomi yang berpotensi, antara lain untuk memajukan kesejahteraan umum, sehingga perlu dikembangkan pemanfaatan sesuai dengan prinsip syari'ah. Dalam Penjelasan Undang-undang Nomor 41 Tahun 2004 disebutkan bahwa praktik wakaf yang terjadi dalam kehidupan masyarakat belum sepenuhnya berjalan tertib dan efisien sehingga dalam berbagai kasus harta benda wakaf tidak terpelihara sebagaimana mestinya, terlantar atau beralih ketangan pihak ketiga dengan cara melawan hukum. Keadaan demikian itu, tidak hanya karena kelalaian / ketidak mampuan nadzir dalam mengelola dan mengembangkan harta benda wakaf tetapi karena juga sikap masyarakat yang kurang peduli atau belum memahami status harta benda wakaf yang seharusnya dilindungi demi untuk kesejahteraan umum sesuai dengan tujuan, fungsi dan peruntukan wakaf.

Hal yang demikian itu dirasakan oleh sebagian dari kaum Muslimin, sebagai landasan utama dalam menghadapi tantangan zaman yang akan manimbulkan kesulitan. Hanya sikap ikhlas beramal selalu menjiwai dalam melaksanakan semua perintah Allah. Maka dari itu perlu adanya motivasi kuat agar sesuatu yang menyangkut masalah perjanjian seperti tanah wakaf perlu dituliskan, sebagaimana firman Allah surat al-Baqarah ayat 282.

Untuk memenuhi kebutuhan hukum dalam rangka pembangunan hukum nasional, Pemerintah telah mengeluarkan Undang-undang Nomor 41 Tahun 2004 tentang Wakaf. Dengan diberlakukannya Undang-Undang ini diharapkan akan terciptanya tertib hukum dan administrasi wakaf guna melindungi harta benda wakaf. Selain itu, ruang lingkup wakaf yang selama ini dipahami secara umum cenderung terbatas pada wakaf benda tidak bergerak seperti tanah dan bangunan. Menurut Undang-Undang ini waqif 
dapat pula mewakafkan sebagian kekayaannya berupa harta benda wakaf bergerak baik berwujud atau tidak berwujud yaitu uang, logam mulia, surat berharga, kendaraan, hak kekayaan intelektual, hak sewa, dan benda bergerak lainnya, waqif dapat mewakafkan melalui lembaga keuangan syari'ah. Akan tetapi untuk lebih fokus, penulis hanya meneliti tentang perwakafan benda tidak bergerak, dalam hal ini perwakafan tanah milik.

Ditinjau dari segi bahasa wakaf berasal dari bahasa Arab waqf yang berasal dari kata waqofa-yaqifu-waqfa yang berarti ragu-ragu, berhenti, memperlihatkan, memperhatikan, meletakan, mengatakan, mengabdi, memahami, mencegah, menahan dan tetap berdiri. Kata al-waqf adalah bentuk kata kerja dari ungkapan waqfu al-syai yang berarti menahan sesuatu. Dalam pengertian secara umum wakaf adalah pemberianyang pelaksanaannya dilakukan dengan jalan menahan (pemilikan) asal (tahbisul ashli), lalu menjadikan manfaatnya berlaku umum. Sedangkan yang dimaksud dengan tahbisulashli ialah menahan barang yang diwakafkan itu agar tidak diwariskan, disewakan dan digadaikan kepada orang lain. Cara pemanfaatanya, menggunakannya adalah sesuai dengan kehendak pemberi wakaf (waqif) tanpa imbalan. ${ }^{+}$

Dalam peristilahan syara' secara umum, wakaf adalah sejenis pemberian yang pelaksanaanya dilakukan dengan jalan menahan (pemilikan) asal (tahbisul ashli), lalu menjadikan manfaatnya berlaku umum, yang dimaksud tahbisul ashli ialah menahan barang yang diwakafkan itu agar tidak diwariskan, dijual, dihibahkan, digadaikan, disewakan, dan sejenisnya. Sedangkan cara pemanfaatannya adalah menggunakan sesuai dengan kehendak pemberi wakaf (waqif) tanpa imbalan.

Para imam empat telah sepakat bahwa waqaf adalah tindakan hukum yang disyari'atkan. Mereka juga sepakat bahwa waqaf masjid, ribath dan seumpamanya yang tidak dimaksudkan menjadikan manfaat waqaf itu kepada seseorang tertentu dan juga dimiliki oleh seseorang.

${ }^{3}$ Farida Prihartin dkk, 2005, Hukum Islam, Zakat dan waqaf, Teori dan Prakteknya di Indonesia, Papas Sinar Sinanti dan Fak. Hukum UI, Jakarta h. 108-109.

${ }^{4}$ Departeman Agama RI,2005, Paradigma Baru Wakaf di Indonesia, Direktorat Pengembangan Zakat dan WakafDepag, Jakarta, h. 1-2.

${ }^{5}$ Syaikh Mahmoud Syaltout dan Syaikh M. Ali as Sayis, Perbandingan Mazhab Dalam Masalah Fiqih cet. keempat, (Jakarta: PT Bulan Bintang), 1987, hlm. 259. 
Wakaf menurut istilah berarti menahan harta yang dapat diambil manfaatnya tanpamusnah seketika dan untuk penggunaan yang mubah, serta dimaksudkan untukmendapatkan keridhaan Allah SWT. ${ }^{6}$

Mengenai dasar hukum wakaf, al-Quran tidak secara tegas menyebutkan, tetapi menurut Syafi'i, Maliki dan Hambali wakaf itu adalah suatu ibadah yang disyariatkan.? Hal ini dapat disimpulkan dari pengertian umum ayat-ayat al-Quran maupun Hadits yang secara khusus menceritakan kasus wakaf di jaman Rasulullah.

Dalam praktiknya, wakaf sudah dilaksanakan sebelum Indonesia merdeka. Pemerintah Indonesia telah menetapkan Undang-undang khusus yang mengatur perwakafan di Indonesia: ${ }^{8}$

1. Undang-undang Nomor 41 tahun 2004 tentang Wakaf. Untuk melengkapi Undang-undang tersebut pemerintah juga menetapkan Peraturan Pemerintah Nomor 42 tahun 2006 tentang Pelaksanaan Undang-undang Nomor 41 tahun 2004.

2. UU nomor 5 Tahun 1960 tentang Peraturan Dasar Pokok-Pokok Agraria, khususnya pasal 5, 14 (1) dan 49, PP No. 28 Tahun 1977 Tentang Perwakafan Tanah Milik.

3. Peraturan Menteri No. 1 Tahun 1978 tentang Peraturan Pelaksanaan PP No. 28 tahun 1977, Instruksi bersama Menag RI dan Kepala BPN No. 4 Tahun 1990 tentang Sertifikat Tanah Wakaf.

4. Badan Pertanahan Nasional No. 630.1-2782 tentang Pelaksanaan Penyertifikatan Tanah Wakaf.

5. Impres No. 1 Tahun 1991 tentang KHI, SK Direktorat BI No. 32/34/KEP/DIR tentang Bank Umum Berdasarkan Prinsip Syariah (pasal 29 ayat 2 berbunyi: Bank dapat bertindak sebagai Lembaga baitul Mal, yaitu menerima dana yang berasal dari zakat, infaq, shadaqah, wakaf, hibah, atau dana sosial lainnya dan

${ }^{6}$ Ahmad Azhar Basyir, Hukum Islam Tentang Wakaf Ijarah Syirkah, (Bandung: Al-Ma'arif, 1987), h. 5. hlm. 179

${ }^{7}$ Hasbi Ash-Shiddiqy, Hukum-Hukum Fiqh Islam (Jakarta: Bulan Bintang, 1978), cet. Kelima,

${ }^{8}$ Direktora Pemberdayaan Wakaf Direktorat Jendral Bimbingan Masyarakat Islam Depag RI. Panduan Pemberdayaan Tanah Wakaf Produktif Strategi di Indonesia (Jakarta: 2007) Hal.31 
menyalurkannya kepada yang berhak dalam bentuk santunan dan atau pinjaman kebajikan (qard al-hasan).

6. SK Direktorat BI No. 32/34/KEP/DIR tentang Bank Perkreditan Rakyat Berdasarkan Prinsip Syariah (pasal 28 berbunyi: BPRS dapat bertindak sebagai lembaga baitul mal, yaitu menerima dana yang berasal dari zakat, infaq, shadaqah, wakaf, hibah, atau dana sosial lainnya dan menyalurkannya kepada yang berhak dalam bentuk santunan dan atau pinjaman kebajikan.

Bagi sebagian besar rakyat Indonesia, tanah menempati kedudukan penting dalam kehidupan mereka sehari-hari. Terlebih lagi bagi rakyat pedesaan yang pekerjaan pokoknya bertani, berkebun atau berladang, tanah merupakan tempat pergantungan hidup mereka. Menurut Van Dijk, tanahlah yang merupakan modal yang terutama, dan untuk bagian terbesar Indonesia, tanahlah yang merupakan modal satu-satunya.' Harta benda wakaf hanya dapat diwakafkan apabila dimiliki dan dikuasai oleh waqif secara sah. Dalam penelitian ini membahas tentang harta benda tidak bergerak khususnya tanah yang dapat diwakafkan yaitu: hak atas tanah.

Hak atas tanah yang dapat diwakafkan antara lain yaitu: hak milik atas tanah baik yang sudah atau belum didaftar. ${ }^{10}$ Dalam Undang-undang No. 5 Tahun 1960 Pasal 20 disebutkan bahwa:

(1) hak milik adalah hak turun-temurun, terkuat dan terpengaruh yang dapat dipunyai orang atas tanah, dengan mengingat ketentuan dalam pasal 6.

(2) hak milik dapat beralih dan dialihkan kepada pihak lain.

Dalam pasal 6 menyatakan bahwa semua hak atas tanah mempunyai fungsi sosial.

\section{B. METODE PENELITIAN}

Penelitian ini menggunakan pendekatan kualitatif, yang prosedur penelitiannya tergolong tipe deskriptif, yaitu prosedur pemecahan masalah

\footnotetext{
${ }^{9}$ Drs. H. Adijani al Alabij SH, Perwakafan Tanah di Indonesia Dalam Teori dan Praktek, cet keempat, (Jakarta: Pt RajaGrafindo Persada, 2002), hlm. 1.

${ }^{10}$ Peraturan Pemerintah No. 42 Tahun 2006 Pasal 17 Ayat (1) huruf a.
} 
yang diselidiki dengan menggambarkan atau melukiskan keadaan obyek penelitian pada saat sekarang, berdasarkan fakta-fakta yang tampak atau sebagaimana adanya. Dalam penelitian ini, tehnik pengambilan sampel adalah dengan menggunakan pendekatan Snowball or Chain Sampling Pendekatan teknik ini menggunakan beberapa orang informan saja terlebih dahulu untuk kemudian memberikan informasi mengenai informasi lain yang mungkin dapat memberikn informasi baru atau tambahan. Obyek atau sampel dalam penelitian ini adalah mengambil lokasi di Kantor Urusan Agama Kecamatan Kalikotes Kabupaten Klaten.

\section{HASIL DAN PEMBAHASAN}

Hasil wawancara dengan ketua takmir Masjid Al-Hidayah, Bapak Suroto, dan pengurus masjid, Bapak Sunarwan, pada hari Jumat 29 April 2016 bahwa Masjid Al-Hidayah didirikan pada tahun 1996 diatas sebidang tanah seluas $183 \mathrm{~m}^{2}$ di Dukuh Ngemplak, Desa Ngemplak, Kecamatan Kalikotes. Di samping sebagai tempat ibadah, Masjid Al-Hidayah juga difungsikan sebagai media dakwah maupun kegiatan kemasyarakatan di antaranya adalah sebagai berikut:

- Sebagai tempat sholat 5 waktu

- Sebagai tempat pengajian rutin jamaah Masjid Al-Hidayah setiap malam Jumat

- Sebagai tempat temu warga

- Sebagai media menyampaikan informasi kepada masyarakat

Kantor Urusan Agama Kecamatan Kalikotes terletak di Dusun Jogodayoh RT 06 RW 01, Desa Kalikotes, Kecamatan Kalikotes, yang berjarak $1500 \mathrm{~m}$ dari Kantor Kecamatan Kalikotes. Letaknya yang sangat strategis, yaitu ditengah-tengah wilayah Kecamatan Kalikotes, sehingga 7 desa yang ada di Kecamatan Kalikotes mudah menjangkau.

Peranan Kantor Urusan Agama yang merupakan ujung tombak Kementerian Agama ditingkat paling bawah sangatlah strategis dan penting bagi visi dan misi Kementerian Agama. Sebagai lembaga yang berhubungan langsung dengan masyarakat, Kantor Urusan Agama dituntut untuk senantiasa siap memberikan pelayanan yang maksimal bagi masyarakat. 
Oleh karena itu pelayanan harus selalu ditingkatkan dengan semangat ikhlas beramal sesuai dengan logo Kementerian Agama menuju pelayanan prima Kantor Urusan Agama.

Disamping tugas pelayanan kepada masyarakat Kantor Urusan Agama juga mempunyai tugas melaporkan segala kegiatan kantor kepada instansi diatasnya yaitu Kantor Kementerian Agama Kabupaten sebagai kontrol dan mengambil kebijakan diwaktu yang akan datang.

Kantor Urusan Agama juga mempunyai tugas pelayanan dan bimbingan kepada masyarakat khususnya dibidang agama Islam. Dalam pelaksanaan tugas yang dimaksud KUA menyelenggarakan fungsinya sebagai pelaksana kebijakan teknis dibidang kepenghuluan, pengembangan keluarga sakinah, pelayanan dan bimbingan dibidang nikah dan rujuk, pengembangan kemitraan umat dan ibadah sosial keagamaan.

Kantor Urusan Agama juga melakukan pendataan tempat ibadah, zakat, haji, dan dibidang perwakafan. Dibidang perwakafan ini, Kepala KUA ditunjuk sebagai Pejabat Pembuat Akta Ikrar Wakaf (PPAIW) sebagaimana yang telah diatur dalam Peraturan Menteri Agama No 1 Tahun 1978 tentang Peraturan Pelaksanaan Pemerintah.

Dalam melaksanakan tugasnya sebagai pelayan masyarakat, Kantor Urusan Agama Kecamatan Kalikotes mempunyai 4 orang Pegawai Negeri Sipil (PNS) dan 3 orang Wiyata Bhakti

\section{Pelaksanaan Perwakafan Tanah Milik yang terjadi di Kecamatan Kalikotes}

Dalam menjalankan proses perwakafan banyak hal yang di perlukan, di antaranya adalah:

1. Orang yang berwakaf (waqif).

2. Harta yang diwakafkan (mauquf).

3. Tujuan wakaf (mauquf a'laih)

4. Pernyataan wakaf (shighat) 
Proses wakaf di KUA

1. Sebelum datang ke kantor KUA waqif bermusyawarah dengan keluarganya. Dengan mempersiapkan waqif, saksi 2 orang, dan nadzir bersama-sama berangkat ke kantor KUA.

2. Waqif, saksi, nadzir pergi ke kua, menghadap kepala KUA selaku PPAIW

3. PPAIW memeriksa persyaratan waqif, persyaratan yang di maksud di sini adalah surat-surat kelengkapan persyaratan perwakafan, seperti surat keterangan dari kepala desa dan sertifikat benda atau benda yang di wakafkan.

4. Nadzir membaca ikrar atau sumpah yang sebelumnya nadzir mengisi pernyataan atau formulir dari PPAIW.

5. Nadzir di sahkan PPAIW

6. Waqif mengucapkan ikrar wakaf di hadapan saksi-saksi dan PPAIW, untuk ikrar wakaf di buat rangkap tiga, yaitu, lembar pertama di simpan PPAIW, lembar 2 di lampirkan pada surat permohonan pendaftaran pada kepala kantor pertanahan kota, lembar 3 di kirim ke pengadilan agama.

7. Waqif, nadzir dan saksi pulang dengan membawa salinan akta ikrar wakaf

8. PPAIW atas nama nadzir menuju ke badan kantor pertanahan nasional di kabupaten dengan membawa berkas permohonan pendaftaran tanah wakaf dengan membawa surat pengantar

9. Kepala kantor pertanahan menyerahkan sertifikat tanah wakaf untuk di catat pada daftar ikrar wakaf dan selanjutnya sertifikat wakaf di serahkan pada nadzir."

\section{Analisis Pelaksanaan Perwakafan Tanah Milik di Kecamatan Kalikotes Sesudah Berlakunya Undang-undang Nomor 41 Tahun 2004}

Mekanisme pelaksanaan perwakafan tanah milik di Kecamatan Kalikotes Kabupaten Klaten secara umum pelaksanaan sudah sesuai

${ }^{11}$ Arsip KUA Kalikotes, Klaten 
dengan Undang-undang Nomor 41 Tahun 2004. Hal ini terbukti dalam proses pelaksanaan perwakafan tanah milik sesuai aturan tersebut. Tetapi dalam pelaksanaannya ada sedikit permasalahan.

Sebelum proses perwakafan atas sebidang tanah yang akan diwakafkan untuk masjid Al Hidayah, di Dukuh Ngemplak Desa Ngemplak Kecamatan Kalikotes, tanah tersebut merupakan warisan dari Rokiman Harno Miarjo, dengan para ahli waris sebagai berikut:

1. Sumarno

2. Sunarti

3. Widodo

4. Surono

5. Sumardi

6. Suramto

7. Suwisno

8. Sri Rejeki

9. Sriaman

Menurut penuturan ketua takmir masjid Al Hidayah yaitu Bapak Suroto bahwa pada bulan Agustus 2003 diadakan musyawarah para ahli waris, dengan hasil musyawarah akan mewakafkan sebagian tanah warisan Alm. Rokiman Harno Miarjo tersebut seluas $\pm 180 \mathrm{~m}^{2}$ untuk lokasi pembangunan masjid dan sebidang tanah yang akan diwakafkan tersebut para ahli waris sepakat diatas namakan salah satu ahli waris yaitu Suwisno.

Namun permasalahan muncul ketika sertifikat sudah jadi pada tanggal 28 Pebruari 2004 dengan HM nomor 1554 yang luasnya $183 \mathrm{~m}^{3}$ atas nama Suwisno, semua ahli waris berkehendak menjadi waqif yang akan mengikrarkan tanah wakaf tersebut. Menurut takmir masjid bahwa permasalahan tersebut berlarut-larut, belum ada penyelesaiannya, walaupun banyak tokoh masyarakat yang menjadi penengahnya. Semua bersikeras untuk menjadi waqif. 
Baru pada awal tahun 2015 setelah para ahli waris dengan didampingi tokoh agama setempat berkonsultasi dengan PPAIW KUA Kecamatan Kalikotes dengan disaksikan oleh Nadzir.

Di mana menghasilkan kesepakatan sebagai berikut:

1. Bahwa ikrar wakaf di wakili oleh salah satu ahli waris yang sudah disepakati sebagai perwakilan/ kuasa ahli waris sebelum proses pensertifikatan tanah wakaf tersebut yaitu Saudara Suwisno

2. Bahwa menurut UU no. 41 tahun 2004 pasal 17 ayat 1, "Ikrar Wakaf dilaksanakan oleh waqif kepada Nadzir di hadapan PPAIW dengan disaksikan oleh 2 (dua) orang saksi.

3. Bahwa menurut UU no. 41 tahun 2004 pasal 21 ayat $1 \& 2$,

a. Ikrar wakaf dituangkan dalam Ikrar wakaf

b. Aklta Ikrar Wakaf sebagaimana di maksud pada ayat (1) paling sedikit memuat:

b. Nama dan identitas waqif

c. Nama dan identitas Nadzir

d. Data \& keterangan harta benda wakaf

e. Pemilik dan harta benda wakaf

f. Jangka waktu wakaf

Karena dalam sertifikat HM. Nomor 1554/ tanah yang akan diwakafkan tersebut atas nama Suwisno, maka untuk pengisian data seperti nama, identitas waqif serta data dan keterangan harta benda waqif harus sesuai dengan yang tertera dalam sertifikat. Hasil musyawarah kedua adalah bahwa semua ahli waris sudah sepakat dan ikhlas kalau wakaf tanah tersebut atas nama saudara Suwisno, sebagai kuasa atas perwaqifan dari para ahli waris. Semua ahli waris menyadari bahwa hal tersebut hanya untuk proses administrasinya, tentang pahala dari wakaf tersebut, pasti Allah SWT yang Maha Mengetahui, karena Allah Maha Adil. 


\section{KESIMPULAN}

Pelaksanaan perwakafan tanah milik yang terjadi di Kecamatan Kalikotes Kabupaten Klaten yang penulis peroleh dalam penelitian, dapat menyimpulkan bahwa secara umum sudah sesuai dengan Undang-undang Nomor 41 Tahun 2004. Hal ini terbukti dari pelaksanaan perwakafan tanah milik sesuai dengan prosedurnya yang berlaku seperti dari awal proses sampai terbitnya sertifikat tanah wakafnya.

Permasalahan dalam pelaksanaan perwakafan tanah milik adalah ketika sertifikat sudah jadi pada tanggal 28 Pebruari 2004 dengan HM nomor 1554 yang luasnya $183 \mathrm{~m}^{3}$ atas nama Suwisno, semua ahli waris berkehendak menjadi waqif yang akan mengikrarkan tanah wakaf tersebut. Hal ini yang tidak sesuai dengan Undang-undang. Baru pada awal tahun 2015 setelah para ahli waris dengan didampingi tokoh agama setempat berkonsultasi dengan PPAIW KUA Kecamatan Kalikotes dengan disaksikan oleh Nadzir. Dimana menghasilkan kesepakatan sebagai berikut:

1. Bahwa ikrar wakaf di wakili oleh salah satu ahli waris yang sudah disepakati sebagai perwakilan/ kuasa ahli waris sebelum proses pensertifikatan tanah wakaf tersebut yaitu Saudara Suwisno

2. Bahwa menurut UU no. 41 tahun 2004 pasal 17 ayat 1, Ikrar Wakaf dilaksanakan oleh waqif kepada Nadzir di hadapan PPAIW dengan disaksikan oleh 2 (dua) orang saksi.

3. Bahwa menurut UU no. 41 tahun 2004 pasal 21 ayat $1 \& 2$

a. Ikrar wakaf dituangkan dalam Ikrar wakaf

b. Akta Ikrar Wakaf sebagaimana dimaksud pada ayat (1) paling sedikit memuat:

1) Nama dan identitas waqif

2) Nama dan identitas Nadzir

3) Data \& keterangan harta benda wakaf

4) Pemilik dan harta benda wakaf 
5) Jangka waktu wakaf

Sehingga Ahli semua waris sudah sepakat dan ikhlas kalau wakaf tanah tersebut atas nama saudara Suwisno, sebagai kuasa atas perwaqifan dari para ahli waris.

\section{REFERENSI}

Abdul aziz Muhammad azzam, fiqh muamalah,(Jakarta, amzah, 2010)

Arsip KUA Kalikotes, Klaten 2015

Adijani al-alabij, perwakafan tanah di Indonesia, (Jakarta, raja grafindo persada, 2002

Prof. H. Mahmud Junus,Tarjamah Al Quran Al Karim, (Bandung: PT.AlMa'arif, 1996),

Abdurrahman, Masalah Perwakafan Tanah Milik dan Kedudukan Tanah Wakaf di Negara Kita, Bandung: Alumni, 1984.

Ahyar, SH, Aspek Hukum Perwakafan Hak Atas Tanah Selain Hak Milik, Jakarta: Badan Pembinaan Hukum Nasional Departemen Kehakiman dan Hak Asasi Manusia RI, 2002.

AlAlabij, Adijani SH, Perwakafan Tanah di Indonesia Dalam Teori dan Praktik, cet keempat, Jakarta: Pt Raja Grafindo Persada, 2002.

Ali, Muhammad Daud, Ekonomi Islam, Zakat dan Wakaf, Jakarta: UI-Press, 1988.

Anshori, Abdul Ghofur, Hukumdan Praktik Perwakafan di Indonesia, Yogyakarta: Pilar Media, 2005.

Basyir, Ahmad Azhar, Hukum Islam, Bandung: Al-Ma'arif, 1987.

Departemen Agama Direktorat Jenderal Bimbingan Masyarakat Islam dan Penyelenggaraan Haji, Pedoman Pejabat Urusan Agama Islam Edisi 2004, Jakarta: 2004. 
Departemen Agama RI Direktorat Jenderal Bimbingan Masyarakat Islam dan Penyelenggaraan Haji Direktorat Pengembangan Zakat dan Wakaf, Nadzir Profesional dan Amanah, t.np., 2005.

Departemen Agama RI DitjenBimas Islam dan Penyelenggaraan Haji, Pedoman Pengelolaan dan Pengembangan Wakaf, Jakarta: t.np., 2004.

Direktorat Pengembangan Zakat dan Wakaf Direktorat Jenderal Bimbingan Masyarakat Islam dan Penyelenggaraan Haji, Paradigma Baru Wakaf di Indonesia, Jakarta: t.np., 2004.

Hamami, Taufiq, Perwakafan Tanah Dalam Politik Hukum Agraria Nasional, Jakarta: PT. Tatanusa, 2003.

https://id.wikipedia.org/wiki/tanah diakses tanggal 29 April 2016

https://id.wikipedia.org/wiki/legislasidiakses tanggal 29 April 2016

Hutagalung, Mura P, Hukum Islam Dalam Era Pembangunan, Jakarta, Penerbit Indonesia Hill co: 1985.

Moleong, Lexy, Metodologi Penelitian Kualitatif, Cet. 8, Bandung: Remaja Rosdakarya, 1997.

Proyek Peningkatan Zakat dan Wakaf Direktorat Jenderal Bimbingan Masyarakat Islam dan Penyelenggaraan Haji, Perkembangan Pengelolaan Wakaf di Indonesia, 2003 